\title{
Application of Ultrahigh Doses of Morphine in Systemic Multiple Epithelioid Hemangioendothelioma without Addiction: A Case Report
}

\author{
Minqiang Liu', Mingfei Ma1, Xinzhong Ning², Renliang $\mathrm{He}^{1 *}$ \\ ${ }^{1}$ Department of Anesthesiology, The Third People's Hospital of Shenzhen, Shenzhen, China \\ ${ }^{2}$ Department of Thoracic Surgery, The Third People's Hospital of Shenzhen, Shenzhen, China \\ Email: *szherenliang@163.com
}

How to cite this paper: Liu, M.Q., Ma, M.F., Ning, X.Z. and He, R.L. (2019) Application of Ultrahigh Doses of Morphine in Systemic Multiple Epithelioid Hemangioendothelioma without Addiction: A Case Report. Case Reports in Clinical Medicine, 8, 285-294.

https://doi.org/10.4236/crcm.2019.811035

Received: October 20, 2019

Accepted: November 8, 2019

Published: November 11, 2019

Copyright $\odot 2019$ by author(s) and Scientific Research Publishing Inc. This work is licensed under the Creative Commons Attribution International License (CC BY 4.0).

http://creativecommons.org/licenses/by/4.0/

\begin{abstract}
Morphine is a potent opioid which is commonly used for relieving cancer pain with strong analgesic properties. Epithelioid hemangioendothelioma (EHE), a rare vascular tumor that can cause severe chronic pain, is usually diagnosed in a surgical biopsy. We describe ultrahigh doses of morphine used in a case of a 17-year-old male who suffered from severe chest pain with systemic multiple EHE. The total dosage of morphine was as high as $92,530 \mathrm{mg}$ given within 164 days. However, we observed no indications that the patient was addicted.
\end{abstract}

\section{Keywords}

Epithelioid Hemangioendothelioma, Morphine, Pain, Addiction

\section{Introduction}

Epithelioid hemangioendothelioma (EHE) is a rare, low-grade malignant vascular tumor that can arise regionally or systemically. Lesions are frequently found in bone, lung, liver, soft tissue, and skin [1] [2]. Most EHE patients are asymptomatic at the time of the diagnosis, but as the disease advances, severe burning pain is the most common symptom [3]. Currently, various therapies, including drug treatment [4] [5], interventional therapy [6], radiotherapy [7], and surgical treatment [8] have been described, however, none of these therapies can completely cure this disease, and pain may become more and more refractory [9]. Morphine is a strong analgesic which has been used for releasing acute or 
chronic pain for a long time [10]. Previous studies have reported that the dose of morphine is determined based on its effect and there is no defined ceiling dosage [11]. Here, we report a case of systemic multiple EHE that underwent prolonged ultrahigh doses of intravenous morphine without significant signs of addiction.

\section{Case Overview}

In August 2013, a 13-year-old man presented to the hospital with the left knee pain after a long walk. His medical and family history revealed no major medical problems. Multiple bone tumors of lower extremity was diagnosed with X-ray examination, after that both multiple body Computed Tomography (CT) and Magnetic Resonance (MR) scan revealed systemic multiple tumors in both lungs and the left third costal (Figure 1), in the right lobe of the liver (Figure 2), the lower section of the left distal femur (Figure 3), the left proximal fibula (Figure 4) and tibia (Figure 5), and the right proximal fibula (Figure 6). A fibula biopsy was administered, and the pathological diagnosis was EHE (Figure 7). Because previous studies had reported cases in which no therapy was administered that patients survived up to 27 years [12] [13], the patient was not treated, and did not show severe pain or other discomfort related to the tumor in the following 4 years.

In January 2017, the patient appeared with intermittent pain in the left chest wall. A resection of the rib where the tumor located was carried out after the next six months, and the postoperative pathology was undoubtedly diagnosed as EHE (Figure 8). However, the intermittent pain did not disappear but turned into persistent pain. In July 2017, a dose of morphine (Morphine Hydrochloride Injection, batch number: 170602-1, NORTHEAST PHARM, Shenyang, China) $10-20 \mathrm{mg}$ was added into a patient controlled intravenous analgesia (PCIA)

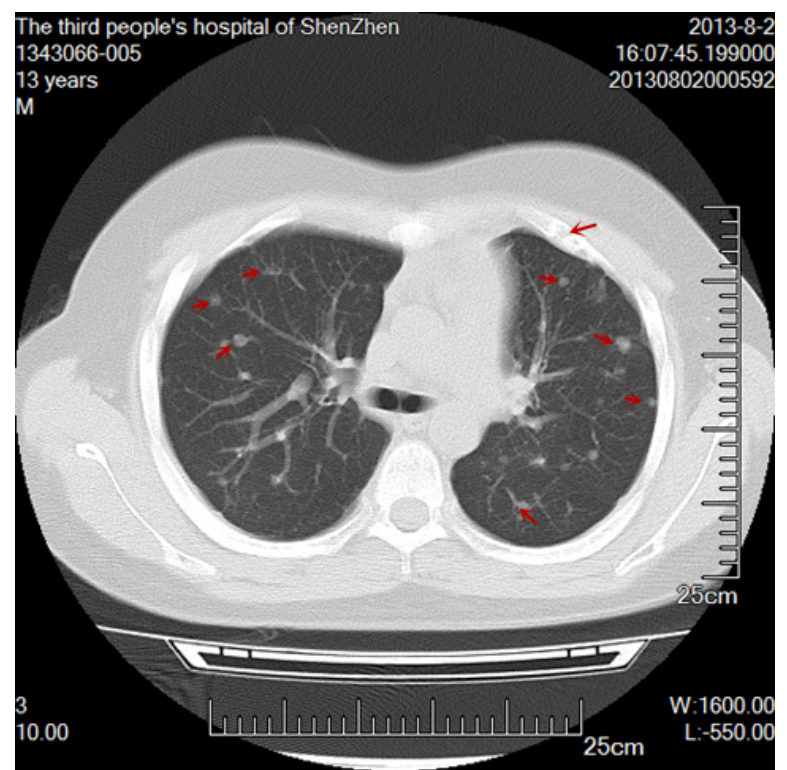

Figure 1. Tumors in both lungs and in the left third costal. CT scans showed multiple metastatic lesions of both lungs, and bone destruction of the left third anterior costal. 


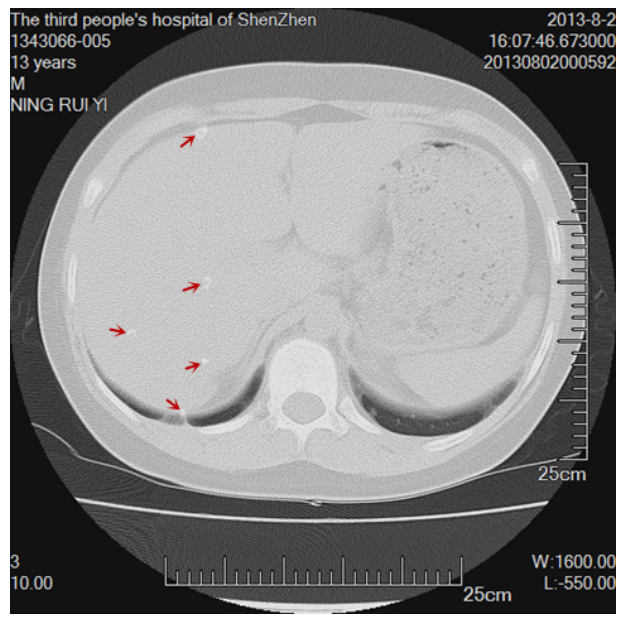

Figure 2. Tumors in the liver. CT scans showed metastatic lesions in the right lobe of the liver.

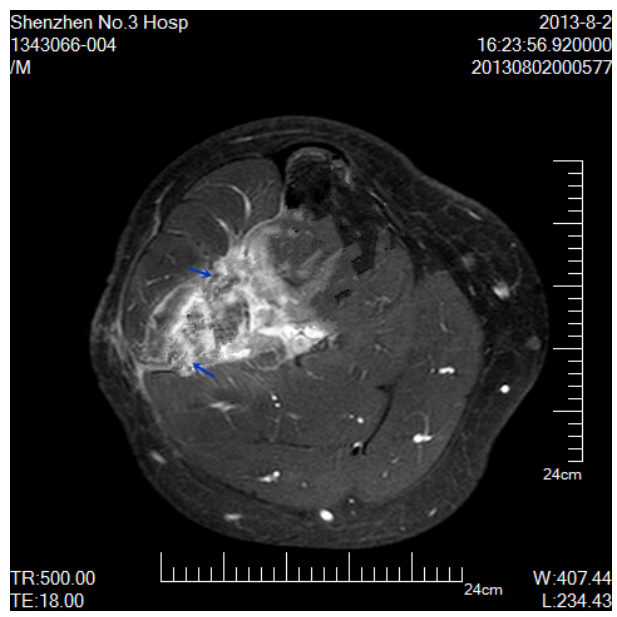

Figure 3. Tumor in the left distal femur. MR scans showed multiple transarticular osteolytic damages in the lower section of the left femur.

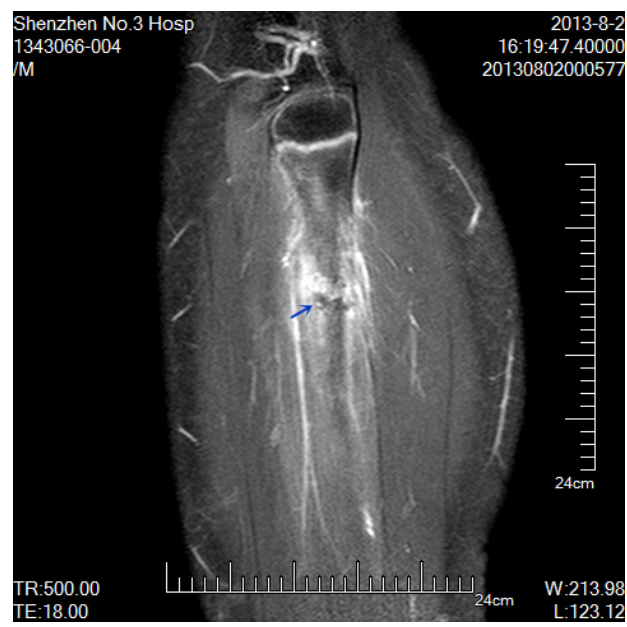

Figure 4. Tumor in the left proximal fibula. MR displayed a medullary lesion with irregular contours and osseous invasion, and an inhomogeneous signal with diffuse post contrast enhancement in the left proximal fibula. 


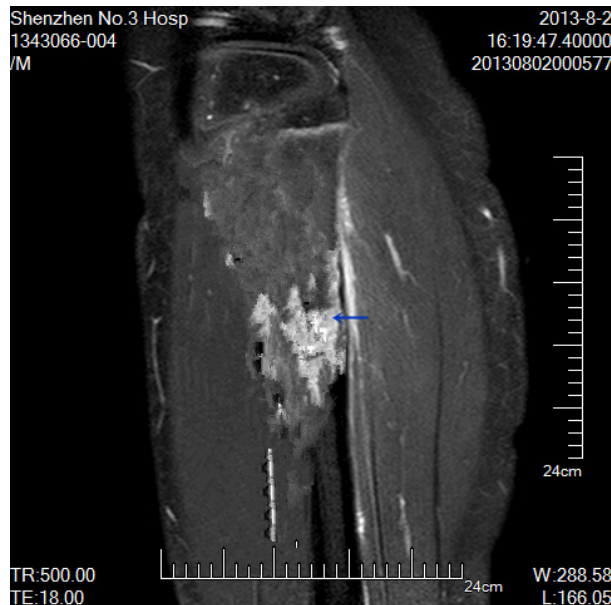

Figure 5. Tumor in the left proximal tibia. $M R$ showed slightly long $T_{1}$ and long $T_{2}$ in the upper section of the left proximal tibia, and the lesion showed obvious enhancement, and long $\mathrm{T}_{2}$ edema signals in the adjacent medullary cavity and muscle tissue.

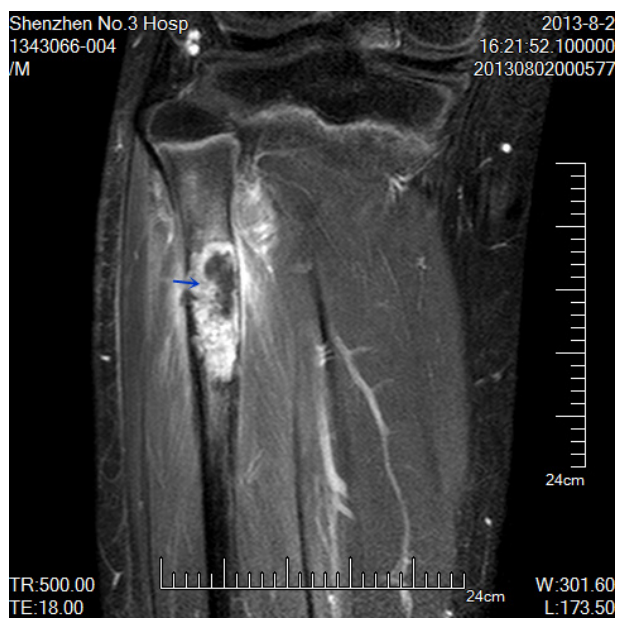

Figure 6. Tumor in the right proximal fibula. MR scans showed osteolytic damage and osseous invasion in the right proximal fibula.

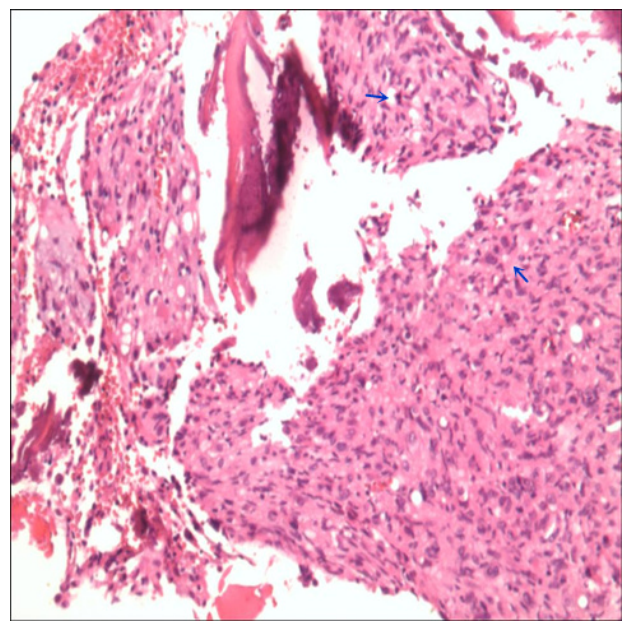

Figure 7. Histopathology of the fibula biopsy. A low-power view demonstrated irregular mesenchymal lesions, distributed in viscous liquid samples or become transparent. 


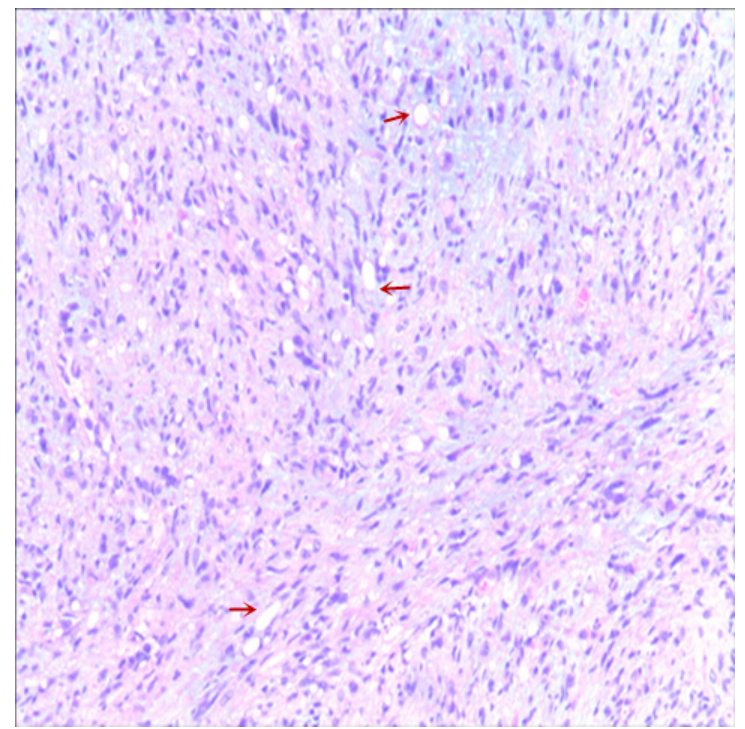

Figure 8. Histopathology of the costal biopsy. A low-power view showed the neoplasm was mainly composed of a mixed proliferation of epithelioid cells and spindle cells some epithelioid cells exhibited clear intracytoplasmic.

device (diluted with normal saline to $150 \mathrm{ml}$, with a loading dose of $2 \mathrm{ml}$, a background dose of $3 \mathrm{ml}$, and an unit additional dose of $3 \mathrm{ml}$ per $15 \mathrm{~min}$ ), in that case, the intensity of analgesia was sufficient for two days, but caused side effects such as dizziness, stomach upset, nausea, and itching. However, the pain aggravated rapidly in 2 weeks, the pain score was evaluated every other day, basically the dosage of morphine increased $10 \mathrm{mg}$ each time at the same volume, and the daily dosage of morphine gradually increased to $120-200 \mathrm{mg}$ in the second month. Despite this increased dose, the patient still complained of mild pain, and could not sleep properly, although he no longer appeared to have nausea or itching. In the third month, the doctors added chlorpromazine $25 \mathrm{mg}$ (12.5 mg orally in the morning, another $12.5 \mathrm{mg}$ intravenously in the evening) and carbamazepine $200 \mathrm{mg}$ ( $100 \mathrm{mg}$ orally per $12 \mathrm{~h}$ ) every day to prevent a rapid rise in the amount of morphine administered. However, the daily dose of morphine still increased quickly to meet the patient's needs for analgesia, the pain score was assessed every day, and the dosage of morphine increased $10 \mathrm{mg}$ per day on average.

In the early November 2017, the daily amount of morphine had risen to 1000 $\mathrm{mg}$ (1000 mg morphine diluted to $150 \mathrm{ml}$ into a PCIA device, parameters set to a loading dose of $3 \mathrm{ml}$, a background dose of $5 \mathrm{ml}$, and a unit dose of $3 \mathrm{ml}$ per 15 $\min$ ). An opioid tolerance (OT) was diagnosed, and opioid addiction and withdrawal tests were conducted. For example, in the Addiction Severity Index Questionnaire [14], the patient's rating scale was only 1 score and the interviewer severity rating got 2 points, indicated that the patient was not addictive. In the Prescription Opioid Addiction Treatment Study [15], result showed that the patient did not need to be treated for addiction. In the Opioid Withdrawal Scale [16], the patient was mental balance, only presented severe pain in the whole 
body without other symptoms such as sanity disorder or fidgety. In this case, a patient controlled epidural analgesia (PCEA) device was inserted to the $6 / 7$ segment of the thoracic spine, and a dose of morphine $200 \mathrm{mg}$ and ropivacaine 200 $\mathrm{mg}$ were administered via an epidural catheter (diluted to $150 \mathrm{ml}$, with a background dose of $3 \mathrm{ml}$, and an unit dose of $3 \mathrm{ml}$ per $15 \mathrm{~min}$ ). This provided adequate pain relief for more than one week, and the daily dosage of intravenous morphine dropped to about $800 \mathrm{mg}$. However, opioid-induced hyperalgesia $(\mathrm{OIH})$ was diagnosed at the second week after the implantation of the PCEA, we started to increase the dose of epidural morphine for $10 \mathrm{mg}$ every day, but that could not effectively relieve the pain from lower limbs. Subsequently, the intravenous morphine dose started to rise again (almost $20 \mathrm{mg} /$ day for addition). At the beginning of the fifth month, the daily total amount of morphine administered reached $1500 \mathrm{mg}$ (venous $1100 \mathrm{mg}$ and epidural $400 \mathrm{mg}$ on average), but still could not effectively relieve the pain. Since ongoing tests continuously excluded the possibility of addiction, an extra single intravenous injection of morphine $100 \mathrm{mg}$ (basically once every $8 \mathrm{~h}$ ) was given whenever both PCIA and PCEA could not provide sufficient analgesia.

The patient died from multiple organ failure (MOF) in late December 2017. Although he was very weak in the last days, he did not complain of pain. The total dosage of all analgesics administered was: morphine $92,530 \mathrm{mg}$, chlorpromazine $2525 \mathrm{mg}$, carbamazepine 19,200 mg, and ropivacaine 14,200 mg within 164 days (Table 1).

\section{Discussion}

Surgical resection is one of the effective ways to treat EHE [17] [18]. It is reported that the 5 -year survival rate after surgical excision is approximately $75 \%$ [19], and this provides a good basis for patients to choose surgical treatment. However, complete resection is impossible in patients with systemic multiple EHE, and surgery cannot radically cure the pain [20]. In this report, the patient was symptom-free for 4 years; although the surgery removed the pain of the lesion sites, it did not solve the patient's pain symptoms. On the contrary, the operation caused the peripheral sensitization of pain and aggravated the progress of obstinate pains. In this condition, the palliative therapy was determined, but

Table 1. Monthly table of the drugs administration.

\begin{tabular}{cccccccc}
\hline Drugs (mg) & $\begin{array}{c}\text { First } \\
\text { month }\end{array}$ & $\begin{array}{c}\text { Second } \\
\text { month }\end{array}$ & $\begin{array}{c}\text { Third } \\
\text { month }\end{array}$ & $\begin{array}{c}\text { Fourth } \\
\text { month }\end{array}$ & $\begin{array}{c}\text { Fifth } \\
\text { month }\end{array}$ & $\begin{array}{c}\text { Last 14 } \\
\text { days }\end{array}$ & Total \\
\hline $\begin{array}{c}\text { Morphine (venous) } \\
\text { Morphine (epidural) }\end{array}$ & 0 & 0 & 0 & 5600 & 7400 & 3100 & 16,100 \\
Chlorpromazine (orally) & 0 & 0 & 337.5 & 387.5 & 375 & 150 & 1250 \\
Chlorpromazine (venous) & 0 & 0 & 337.5 & 387.5 & 375 & 175 & 1275 \\
Carbamazepine (orally) & 0 & 0 & 5400 & 6200 & 6000 & 1600 & 19,200 \\
Ropivacaine (epidural) & 0 & 0 & 0 & 5200 & 6600 & 2400 & 14,200 \\
\hline
\end{tabular}


first of all, it was very important to use an effective measure to deal with pain that could positively affect the quality of life of the patient.

It is well-recognized that morphine is the safest and most effective analgesic for releasing chronic, cancer pain, and there is no ceiling effect [21]. Though extended exposure to morphine can lead to some drug-related adverse reactions such as analgesic tolerance, drug addiction, hyperalgesia, etc., a research suggests that long-term, high-dose morphine use was well-tolerated, and could improve patient's life quality without affecting life expectancy [22]. In a nine-month study, Chatham [23] reported that a daily dose of morphine over $1200 \mathrm{mg}$ was safe. Moreover, Lin [24] found that morphine could also induce the apoptosis of cancer cells in a chronic high-dose morphine treatment study, and this effect was beneficial to patient recovery. Thus, we defined the dose of morphine according to the patient's need. In this case, the initial application of morphine was directly prescribed by the anesthesiologist. But with the aggravation of patients' pain, our anesthesia department was unable to provide sufficient amount of morphine, thus the anesthesiologist communicated with the patient's chief physician every morning after pain assessment, and informed the doctor in charge of the expected morphine of the day. The nurse on duty went to the pharmacy to receive the medicine with the red prescription, then told the anesthesiologist to give analgesic treatment and psychotherapy.

Currently, both OT and OIH are common in patients receiving long-term opioid management for cancer pain. OT is defined as a physiological state in which the body adapts to the medication after frequent exposure and requires higher doses to achieve the same effect. OIH is a phenomenon of enhanced pain sensitization to stimulation [25]. The mechanisms responsible for OT and OIH are complicated, including mesenchymal stem cells attenuation, glutamate release in the spinal cord, descending facilitation, etc. [26] [27] [28]. Drugs such as cyclooxygenase-2 inhibitors, ketamine, and dextromethorphan have been proposed to help manage $\mathrm{OIH}$ [27] [28], but there are anxieties about the potential organ damages caused by these medicines. To reduce the interactions among a variety of drugs, and to acquire an accurate estimation of analgesia addiction, we did not add other medications to deal with these complications.

Addiction is another common adverse reaction after long-term opioid treatment. Addicted patients usually exhibit drug-seeking behavior due to depression or anxiety [29]. The activation of the mesolimbic dopaminergic pathway, the inflammation and degeneration of neurons, including long-term potentiation and long-term depression of the glutamatergic synapses are thought to be contributed to the development of addiction [29] [30]. Since our patient was always clear in consciousness, and did not appear any abnormal features suggestive of addiction, we concluded that the amount of morphine should not be limited under strict addiction assessments.

\section{Conclusion}

In summary, our practice represents a prolonged ultrahigh dose of morphine 
used in a systemic multiple EHE patient without addiction. But more case series or comparative studies are needed to evaluate the outcome of this approach, and a well-constructed evaluation scale such as the limits of OT and OIH should be adopted to assess the potential complications as well.

\section{Acknowledgements}

We would like to thank the Journal of Zhejiang University English Polishing Service for help with English use during manuscript preparation.

\section{Conflicts of Interest}

The authors declare no conflicts of interest regarding the publication of this paper.

\section{References}

[1] Studer, L.L. and Selby, D.M. (2018) Hepatic Epithelioid Hemangioendothelioma. Archives of Pathology \& Laboratory Medicine, 142, 263-267. https://doi.org/10.5858/arpa.2016-0171-RS

[2] Treska, V., Daum, O., Svajdler, M., Liska, V., Ferda, J. and Baxa, J. (2017) Hepatic Epithelioid Hemangioendothelioma-A Rare Tumor and Diagnostic Dilemma. In Vivo, 31, 763-767. https://doi.org/10.21873/invivo.11128

[3] Saste, A., Cabrera Fernandez, D.F., Gulati, R. and Gamalski, S. (2015) A Trimodality Approach in the Management of Metastatic Low-Grade Epithelioid Hemangioendothelioma of the Bone. BMJ Case Reports, 2015, bcr2015210196. https://doi.org/10.1136/bcr-2015-210196

[4] Lau, A., Malangone, S., Green, M., Badari, A., Clarke, K. and Elquza, E. (2015) Combination Capecitabine and Bevacizumab in the Treatment of Metastatic Hepatic Epithelioid Hemangioendothelioma. Therapeutic Advances in Medical Oncology, 7, 229-236. https://doi.org/10.1177/1758834015582206

[5] Zheng, Z., Wang, H., Jiang, H., Chen, E., Zhang, J. and Xie, X. (2017) Apatinib for the Treatment of Pulmonary Epithelioid Hemangioendothelioma: A Case Report and Literature Review. Medicine (Baltimore), 96, e8507. https://doi.org/10.1097/MD.0000000000008507

[6] Sebastian, A.S., Adair, M.J., Morris, J.M., Khan, M.H., Arndt, C.A. and Nassr, A. (2015) Minimally Invasive Treatment of a Painful Osteolytic Lumbar Lesion Secondary to Epithelioid Hemangioendothelioma. Global Spine Journal, 5, 135-139. https://doi.org/10.1055/s-0034-1387198

[7] Albakr, A., Schell, M., Drew, B. and Cenic, A. (2017) Epithelioid Hemangioendothelioma of the Spine: Case Report and Review of the Literature. Journal of Spine Surgery, 3, 250-259. https://doi.org/10.21037/jss.2017.05.05

[8] Ennouhi, M.A., Guerrouani, A. and Moussaoui, A. (2018) Epithelioid Hemangioendothelioma, an Uncommon Tumor of the Eyelid: A Case Report. Journal of Stomatology, Oral and Maxillofacial Surgery, 119, 40-43.

https://doi.org/10.1016/j.jormas.2017.10.001

[9] Harada, J., Yoshida, H., Ueda, J., Mamada, Y., Taniai, N., Mineta, S., Yoshioka, M., Kawano, Y., Shioda, Y. and Uchida, E. (2011) Malignant Hepatic Epithelioid Hemangioendothelioma with Abdominal Pain due to Rapid Progression. Journal of Nippon Medical School, 78, 246-251. 
[10] Mark, J., Argentieri, D.M., Gutierrez, C.A., Morrell, K., Eng, K., Hutson, A.D., Mayor, P., Szender, J.B., Starbuck, K., Lynam, S., Blum, B., Akers, S., Lele, S., Paragh, G., Odunsi, K., de Leon-Casasola, O., Frederick, P.J. and Zsiros, E. (2018) Ultrarestrictive Opioid Prescription Protocol for Pain Management After Gynecologic and Abdominal Surgery. JAMA Network Open, 1, e185452. https://doi.org/10.1001/jamanetworkopen.2018.5452

[11] Kumar, V., Garg, R., Bharati, S.J., Gupta, N., Bhatanagar, S., Mishra, S. and Balhara, Y.P. (2015) Long-Term High-Dose Oral Morphine in Phantom Limb Pain with No Addiction Risk. Indian Journal of Palliative Care, 21, 85-87. https://doi.org/10.4103/0973-1075.150198

[12] Aalae, I.S. and Jakate, S. (2005) Right Upper Quadrant Pain and Fever in a 41-Year-Old Man. Epithelioid Hemangioendothelioma of the Liver with Metastasis to Porta Hepatis Lymph Nodes and Lung. Archives of Pathology \& Laboratory Medicine, 129, e134-e135.

[13] Makhlouf, H.R., Ishak, K.G. and Goodman, Z.D. (1999) Epithelioid Hemangioendothelioma of the Liver: A Clinicopathologic Study of 137 Cases. Cancer, 85, 562-582.

https://doi.org/10.1002/(SICI)1097-0142(19990201)85:3<562::AID-CNCR7>3.0.CO; $\underline{2-\mathrm{T}}$

[14] Saffier, K., Colombo, C., Brown, D., Mundt, M.P. and Fleming, M.F. (2007) Addiction Severity Index in a Chronic Pain Sample Receiving Opioid Therapy. Journal of Substance Abuse Treatment, 33, 303-311. https://doi.org/10.1016/j.jsat.2006.12.011

[15] Weiss, R.D. and Rao, V. (2017) The Prescription Opioid Addiction Treatment Study: What Have We Learned. Drug and Alcohol Dependence, 173, S48-S54.

https://doi.org/10.1016/j.drugalcdep.2016.12.001

[16] Cooper, Z.D., Johnson, K.W., Pavlicova, M., Glass, A., Vosburg, S.K., Sullivan, M.A., Manubay, J.M., Martinez, D.M., Jones, J.D., Saccone, P.A. and Comer, S.D. (2016) The Effects of Ibudilast, a Glial Activation Inhibitor, on Opioid Withdrawal Symptoms in Opioid-Dependent Volunteers. Addiction Biology, 21, 895-903. https://doi.org/10.1111/adb.12261

[17] Oshima, N., Terajima, H. and Hosotan, I.R. (2009) Surgical Therapy for a Solitary Form of Hepatic Epithelioid Hemangioendothelioma: A Long-Term Survival Case. Case Reports in Gastroenterology, 3, 214-221. https://doi.org/10.1159/000227734

[18] Ciliberti, M.P., Caponio, R., Pascali, A., Matichecchia, G. and Lioce, M. (2015) A Rare Case of Intravascular Epithelioid Hemangioendothelioma of the Cephalic Vein Treated with Surgery and Postoperative Radiation Therapy: A Case Report and Review of the Literature. Journal of Medical Case Reports, 9, 91. https://doi.org/10.1186/s13256-015-0565-0

[19] Soape, M.P., Verma, R., Payne, J.D., Wachtel, M., Hardwicke, F. and Cobos, E. (2015) Treatment of Hepatic Epithelioid Hemangioendothelioma: Finding Uses for Thalidomide in a New Era of Medicine. Case Reports in Gastrointestinal Medicine, 2015, Article ID: 326795. https://doi.org/10.1155/2015/326795

[20] Mehrabi, A., Kashfi, A., Fonouni, H., Schemmer, P., Schmied, B.M., Hallscheidt, P., Schirmacher, P., Weitz, J., Friess, H., Buchler, M.W. and Schmidt, J. (2006) Primary Malignant Hepatic Epithelioid Hemangioendothelioma: A Comprehensive Review of the Literature with Emphasis on the Surgical Therapy. Cancer, 107, 2108-2121. https://doi.org/10.1002/cncr.22225

[21] Nosek, K., Leppert, W., Nosek, H., Wordliczek, J. and Onichimowski, D. (2017) A Comparison of Oral Controlled-Release Morphine and Oxycodone with Transdermal Formulations of Buprenorphine and Fentanyl in the Treatment of Severe Pain 
in Cancer Patients. Drug Design, Development and Therapy, 11, 2409-2419. https://doi.org/10.2147/DDDT.S141007

[22] Bercovitch, M. and Adunsky, A. (2004) Patterns of High-Dose Morphine Use in a Home-Care Hospice Service: Should We Be Afraid of It? Cancer, 101, 1473-1477. https://doi.org/10.1002/cncr.20485

[23] Chatham, M.S., Dodds Ashley, E.S., Svengsouk, J.S. and Juba, K.M. (2013) Dose Ratios between High Dose Oral Morphine or Equivalents and Oral Methadone. Journal of Palliative Medicine, 16, 947-950. https://doi.org/10.1089/jpm.2012.0434

[24] Lin, X., Wang, Y.J., Li, Q., Hou, Y.Y., Hong, M.H., Cao, Y.L., Chi, Z.Q. and Liu, J.G. (2009) Chronic High-Dose Morphine Treatment Promotes SH-SY5Y Cell Apoptosis via c-Jun N-Terminal Kinase-Mediated Activation of Mitochondria-Dependent Pathway. The FEBS Journal, 276, 2022-2036.

https://doi.org/10.1111/j.1742-4658.2009.06938.x

[25] Donaldson, R., Sun, Y., Liang, D.Y., Zheng, M., Sahbaie, P., Dill, D.L., Peltz, G., Buck, K.J. and Clark, J.D. (2016) The Multiple PDZ Domain Protein Mpdz/MUPP1 Regulates Opioid Tolerance and Opioid-Induced Hyperalgesia. BMC Genomics, 17, 313. https://doi.org/10.1186/s12864-016-2634-1

[26] Hua, Z., Liu, L., Shen, J., Cheng, K., Liu, A., Yang, J., Wang, L., Qu, T., Yang, H., Li, Y., Wu, H., Narouze, J., Yin, Y. and Cheng, J. (2017) Mesenchymal Stem Cells Reversed Morphine Tolerance and Opioid-induced Hyperalgesia. Scientific Reports, 7, Article No. 40978. https://doi.org/10.1038/srep40978

[27] Patch, R.K., Eldrige, J.S., Moeschler, S.M. and Pingree, M.J. (2017) Dexmedetomidine as Part of a Multimodal Analgesic Treatment Regimen for Opioid Induced Hyperalgesia in a Patient with Significant Opioid Tolerance. Case Reports in Anesthesiology, 2017, Article ID: 9876306. https://doi.org/10.1155/2017/9876306

[28] Woodward, O.B., Naraen, S. and Naraen, A. (2017) Opioid-Induced Myoclonus and Hyperalgesia Following a Short Course of Low-Dose Oral Morphine. British Journal of Pain, 11, 32-35. https://doi.org/10.1177/2049463716664371

[29] Borjkhani, M., Bahrami, F. and Janahmadi, M. (2018) Computational Modeling of Opioid-Induced Synaptic Plasticity in Hippocampus. PLoS ONE, 13, e0193410. https://doi.org/10.1371/journal.pone.0193410

[30] Chen, S.L., Tao, P.L., Chu, C.H., Chen, S.H., Wu, H.E., Tseng, L.F., Hong, J.S. and Lu, R.B. (2012) Low-Dose Memantine Attenuated Morphine Addictive Behavior through Its Anti-Inflammation and Neurotrophic Effects in Rats. Journal of Neuroimmune Pharmacology, 7, 444-453. https://doi.org/10.1007/s11481-011-9337-9 